\title{
GE3D: A Virtual Campus for Technology-Enhanced Distance Learning
}

\author{
doi:10.3991/ijet.v5i3.1388 \\ Jean GRIEU, Florence LECROQ, Patrick PERSON, Thierry GALINHO, Hadhoum BOUKACHOUR \\ University of Le Havre, Le Havre, France
}

\begin{abstract}
A lot of learning systems platforms are used all over the world. But these conventional E-learning platforms aim at students who are used to work on their own. Our students are young (19 years old -22 years old), and in their first year at the university. Following extensive interviews with our students, we have designed GE3D, an E-learning platform, according to their expectations and our criteria. In this paper, we describe the students' demands, resulting from the interviews. Then, we describe our virtual campus. Even if our platform uses some elements coming from the 3D games world, it is always a pedagogical tool. Using this technology, we developed a 3D representation of the real world. GE3D is a multi-users tool, with a synchronous technology, an intuitive interface for end-users and an embedded Intelligent Tutoring System to support learners. We also describe the process of a lecture on the Programmable Logic Controllers (PLC's) in this new universe.
\end{abstract}

Index Terms-component: virtual reality, TechnologyEnhanced Learning, learning systems platforms, engineering education, Intelligent Tutoring System, Multi Agent System .

\section{INTRODUCTION}

There are so many learning management systems (LMS) all over the world, that to choose one is difficult. Among them, Moodle is the one mostly used [1]. Five years ago, our university decided to implement it for all syllabi. Until now, it is a statement of fact that this tool is at best underused or at worst unused [2]. There are many reasons explaining this lack of interest. The most important are the learner's loneliness, the lack of ergonomics and the way it is used: like a bookcase or a set of compartments for documents. This platform must be an exchange and communication area, supporting knowledge acquisition by links established between end-users, belonging to the same interest community. The subject taught and the students' profiles are decisive factors in the choice of the shape and functionalities given by the LMS. In order to explore the expectations of the students, their way of life, their uses of Internet and their computer equipment, an assessment of their needs was conducted. Following the results obtained and according to many studies on the value added by three dimensional environments (3D) in e-learning [3-7], we have designed GE3D, a virtual campus with the SCOL technology [8].

Finally, we will focus on the lack of the individual tracking and the communication with the learner, which generate a risk of disinterest and eventually desertion. For Carr [9], the desertion rate is over 10 to $20 \%$ when compared to face-to-face classroom learning. How can we prevent this risk in the knowledge acquisition process? The intelligent tutoring system (ITS) embedded in GE3D, based on a multi-agent system (MAS), provides solutions. It allows a more accurate interactivity, keeping the learner in touch.

\section{SURVEYING THE NEEDS OF THE STUDENTS}

The students were surveyed for their expectations and criteria for a learning system platform [10]. They are young undergraduates (19 years old - 22 years old). There are more boys than girls preparing this technological diploma (Department of Electrical Power and Industrial Computing). 220 students were surveyed for the report.

The students are playing 3D games (90\%), by network (55\%). The majority of students have personal access to internet (68\%), with a high speed connection (50\%). This connection is often used: every day (37\%), from one to several times per week (33\%). The time spent for each connection is: 1 hour (26\%), from 1 to 3 hours (29\%), and more than 3 hours (17\%). They use the connection at first for entertainment then for communication and finally for work. They communicate with an instant messenger software (e.g. yahoo messenger) (62\%) and by e-mail (74\%).

After the general questions, we asked them for the qualities of a "good web site". The first quality is quickness, followed by the content, and then the clarity. A lot of our students $(69 \%)$ know the web site of the university, but a large number (72\%) does not know the Moodle platform and more do not use it (85\%). For our students, a LMS must be in addition to the traditional courses (85\%), instead of a unique and complete solution (9\%). For knowledge acquisitions, they consider facing the teacher as essential (62\%). For them, IT isolates people rather than getting them closer, and improves communications rather than deteriorating them. In their expectations of an ideal numerical campus, our students want first to get their time schedule, then complements of the traditional courses, then more exercises and the old exams with the solutions. They want a "hot-line" with the teachers and a communication area with them, a simple but quick web site, and finally they want to access simultaneously with other students on the site.

Following this survey, a first 3D virtual campus prototype was presented to the students, with the topic concerning Programmable Logic Controllers (PLC's). We can summarize the results of the second interview by the following:

- They want a serious 3D environment for classrooms, without anything likely to disturb them.

- For the practical area, they want a room with an industrial look. They want to see the PLC's with an 
operative part. They want to interact with the system by pressing buttons and observing what happens. In this area, they want to realize something by themselves.

- They do not want a sophisticated avatar for their own representation in the $3 \mathrm{D}$. They just want a simple shape textured with their photo on it. This way, they can recognize who is here at the same time. They think that a human shaped avatar does not give additional information in this virtual world.

- The audio component is essential, but reserved for the teacher. During a session, students put questions by text in the chat module and the professor answers by audio to all the students.

Now, taking into account all the students' recommendations, we will present the final version of a virtual campus for students.

\section{GE3D: A SOLUTION}

A virtual campus is a set of different rooms in which various teaching and training activities can be done: lectures, exercises, group works, exams...The choice of a virtual campus rather than a traditional LMS (e.g. Moodle) is obvious for the students in the Department of Electrical Power and Industrial Computing. They are experts in playing 3D games on network. According to their expectations and our criteria, we have designed GE3D, with the SCOL technology. The choice of that technology was driven by the specifications: Web3D technology, open source to allow our own developments, platform independent, with client-server architecture.

\section{A. Description of the $3 D$ world}

In the first area (Fig. 1), we can find in the 3D part a mail box to send e-mail, a board for the time tables, a board for the assessment marks, a board for the system help, a clock to be on time, a door to access other areas.
In the lower part of the window, we can find on the left the numbers and the names of the connected people, several functions for login, for choosing a representative photo for the avatar, for a private chat between two users and a general map of the site. Under the blue scrolling banner announcing the last news, we can find a public chat available for all the users.

Fig. 2 shows the amphitheatre where synchronous presentations can be done. On the right is a large screen on which videos, slides or drawings can be sent by the teacher. Learners take place on the seats in front of the screen. Only the teacher can use the audio line. In the lower part of the window, we can see the public chat where students ask questions to the teacher.

The next room (Fig. 3) shows the industrial part of the site. Here is a SIEMENS PLC, the same used by our students in our department. A simple actuator is presented here by a cylinder and its Sequential Function Chart (SFC) program. This 3D environment allows the users to undertake activities in a synchronous way. For example, when one student activates the SFC, the rod of the cylinder moves according to its evolution cycle. At the same time, all the connected users can see synchronously the cylinder movements and the SFC evolutions. Other simple exercises are available in the same room. If a student can complete with success all the exercises, then he can access videos of five more sophisticated industrial processes made with a commercial software [11-12]. In addition to the videos, the student gets the specifications of each industrial process. When they have prepared their own programs of the process, they come back to reality in the real PLC's room where they can test them. As always, if they meet some difficulties, they can get help from peers, teacher or intelligent tutoring system (ITS) through the chat.

Having described the resources available in GE3D, we will now explain how to fit them in a pedagogical scenario.

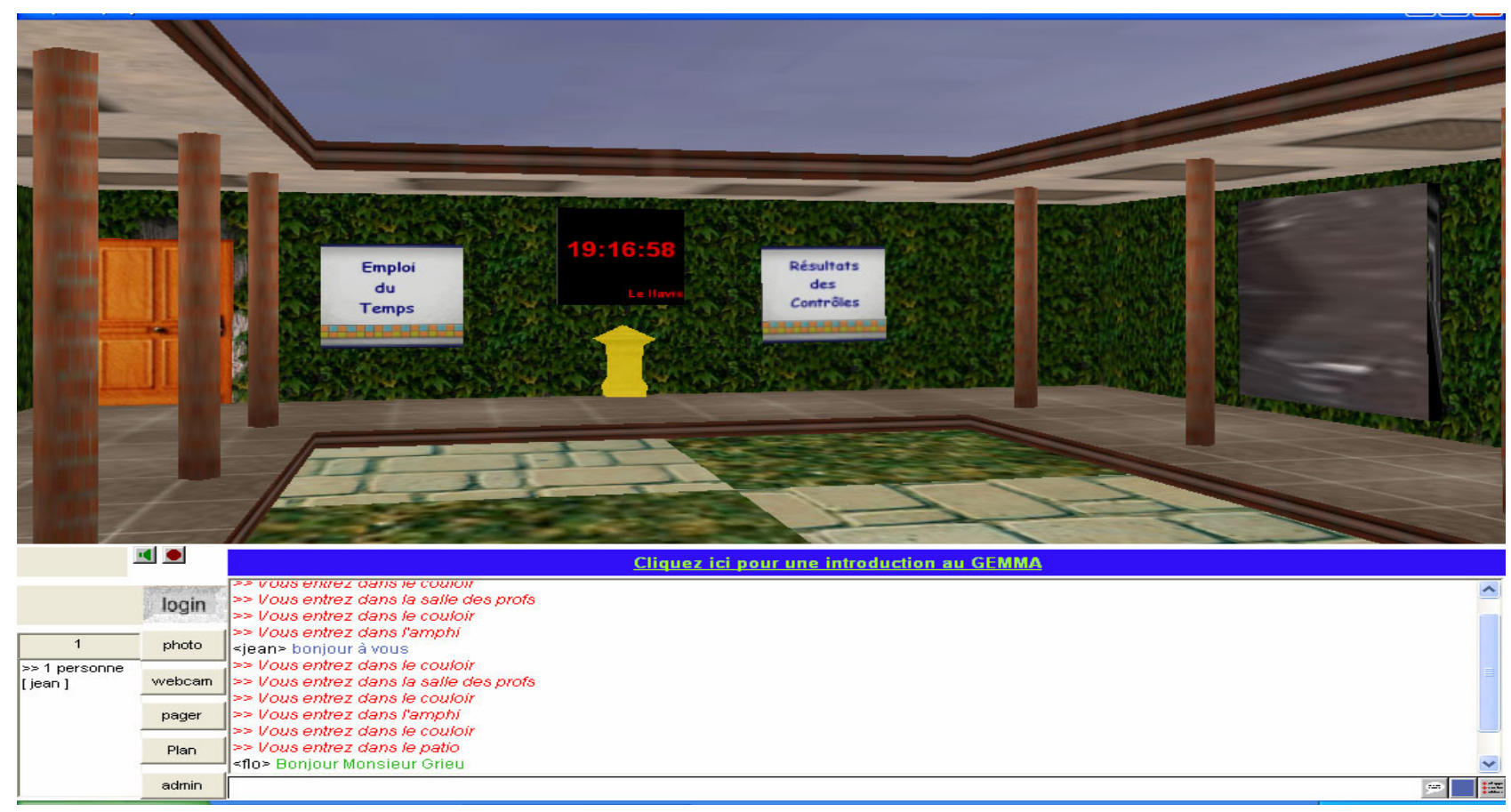

Figure 1. Entrance of the virtual campus 


\section{B. The pedagogical scenario}

A typical structure of a course on PLC's could be the following:

1. An appointment is given to all the students at the amphitheatre.

2. Before entering, the students download lecture notes with gaps they have to fill during the lecture.

3. During the presentation, the lecturer can use the screen to upload notes or slides. He can also use a white board and a microphone for the audio. Meanwhile the students complete the lecture notes and put questions through public chat if needed. The teacher answers the questions by audio for all the students.
4. After the lecture, the students answer an online multiple choice question test. In case of success, they can access the industrial part of GE3D. If they fail the test, they replay the recorded lecture.

5. In the Industrial room, the tutor demonstrates how to use the equipments and explains what he is expecting from the learners. He leaves the students working on their own but remain available to answer the questions.

6. When the students complete all the given exercises, they can download specifications and videos of a complex industrial process simulator.

7. After programming the process the students can join the teacher to validate their solutions on real PLC's.
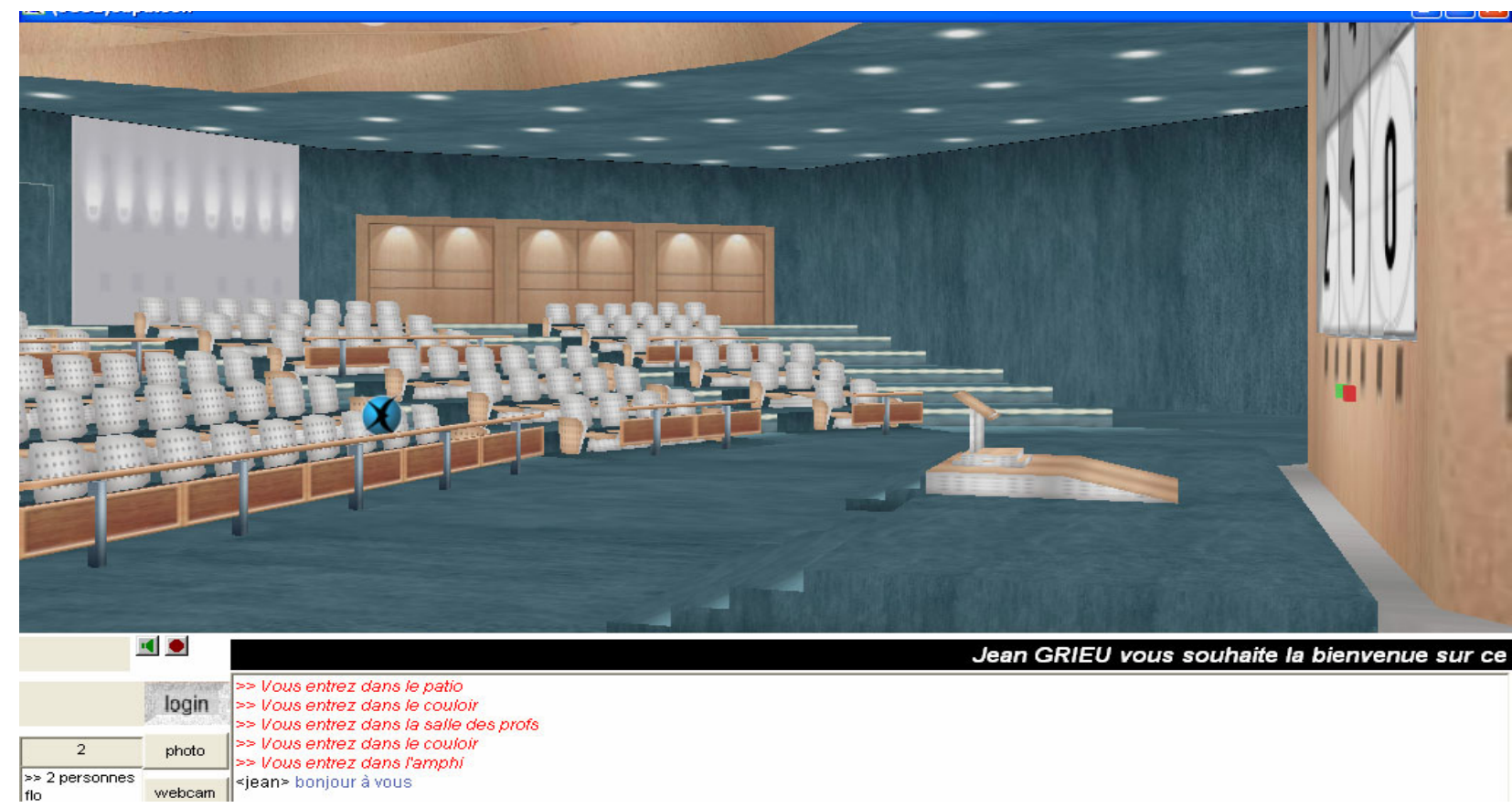

Figure 2. Amphitheatre with an avatar

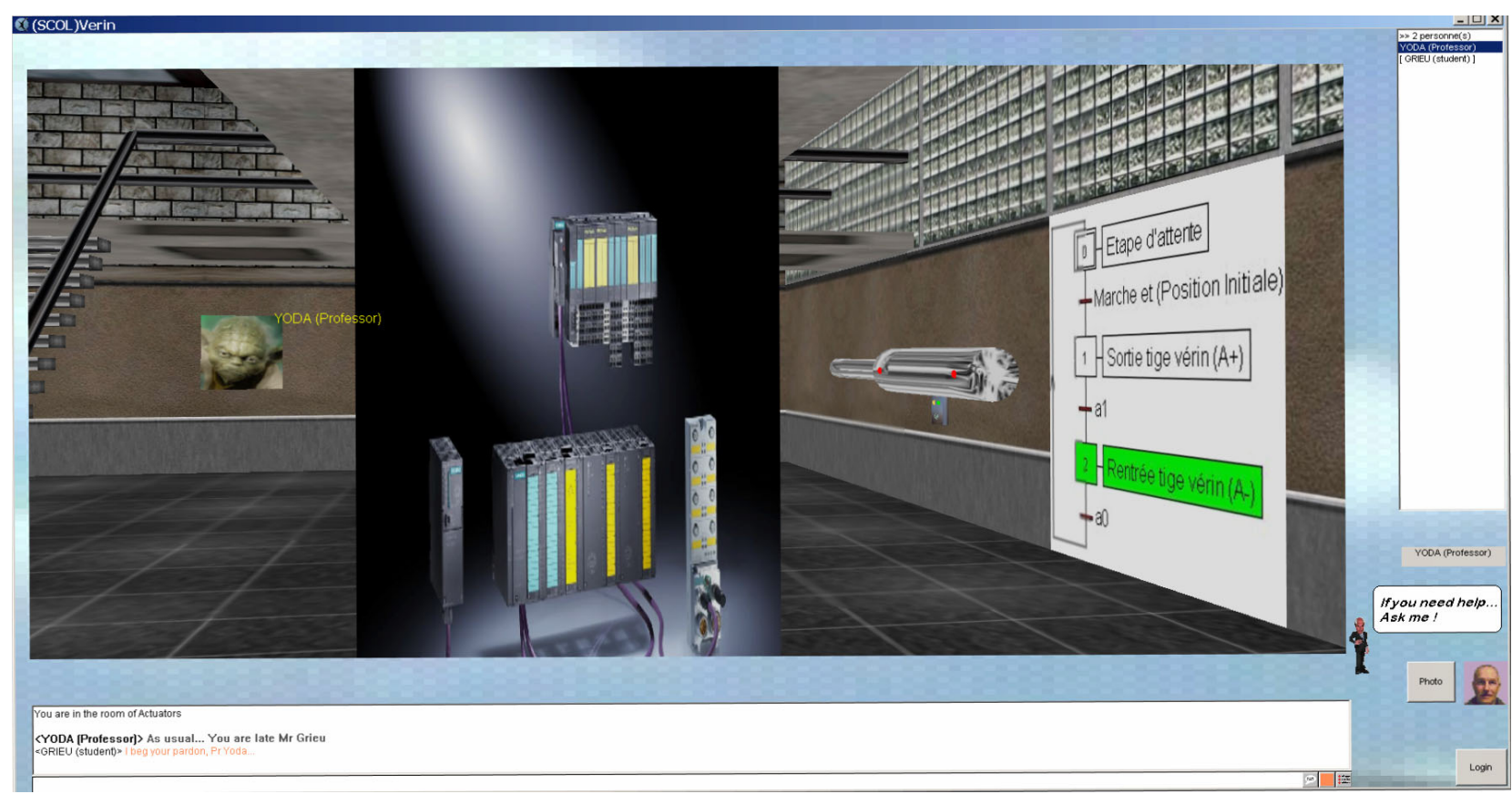

Figure 3. Industrial area in GE3D 
The interviews further revealed that although students can collaborate with each other in GE3D they demand more contact and communication with teachers. In this regard, with the aim of helping tutors and students, we have developed an intelligent tutoring system (ITS) in GE3D.

\section{Intelligent Tutoring System to prevent students from giving up}

Broadly defined, an intelligent tutoring system (ITS) is educational software containing an artificial intelligence component. The software tracks students' work, tailoring feedback and hints along the way. By collecting information on a particular student's performance, the software can make inferences about strengths and weaknesses, and can suggest additional work [13].

The three main parts of the Intelligent Tutoring System (ITS) are (Fig. 4):

- Four Human-Computer Interfaces (HCI) in blue.

- Three knowledge parts in green.

- A four layers hierarchic multiagent system (MAS) in red, developed with Jade [14].

Our ITS follows the four components proposed by Wenger [15] which are knowledge of the domain, student model, teaching model and user interface:

1. Knowledge of the domain with domain ontology, semantic proximity measure and composite factual semantic features.

2. Student model using case-based reasoning [16-17]. During a first step, supervised learning with a group of students generates input from the interpretation layer to the base of scenarii.

3. Teaching models are associated to student models during the supervised learning steps. Decision layer must produce the most appropriate answer for the learner from the data retrieved in the base of scenarii. That layer may also call a human tutor when needed.

4. Interfaces for learners and course creator are detailed in previous sections. A $3 \mathrm{D}$ visualisation allows developers to see the evolutions and messages exchanged inside MAS.

Users inputs from human-computer interface are sent to the ITS. All inputs are transformed into a unique data structure called composite factual semantic feature (CFSF). The successive composite factual semantic features are the inputs of the representation layer of the MAS. In linguistics, a semantic feature is a meaningful component used in text analysis. Here, it is used in another context. A composite factual semantic feature is still a meaningful component. But a CFSF is also an observable fact which is composite because it is composed of a few items. An item is a property-value pair. Three items are compulsory for a CFSF: Type, Name and Date. The generic model of CFSF is:

$<$ !ELEMENT CFSF (Type, Name, Date, Item+) >

The symbol + at the end of Item means that the number of items could be a given value from 1 to $n$ and that number depends on the Type of CFSF. The couple TypeName is the key of the CFSF. Duplicate keys are not allowed. CFSFs are written in XML:

\section{$<\mathrm{CFSF}>$}

$<$ Type $>$ valueType $<$ Type $>$

$<$ Name $>$ valueName $<$ /Name $>$

$<$ Date $>$ valueDate $</$ Date $>$

$<$ Item1 $>$ value $1</$ Item1 $>$

$\ldots \ldots$

$<$ ItemN $>$ valueN $</$ ItemN $>$

$</ \mathrm{CFSF}>$

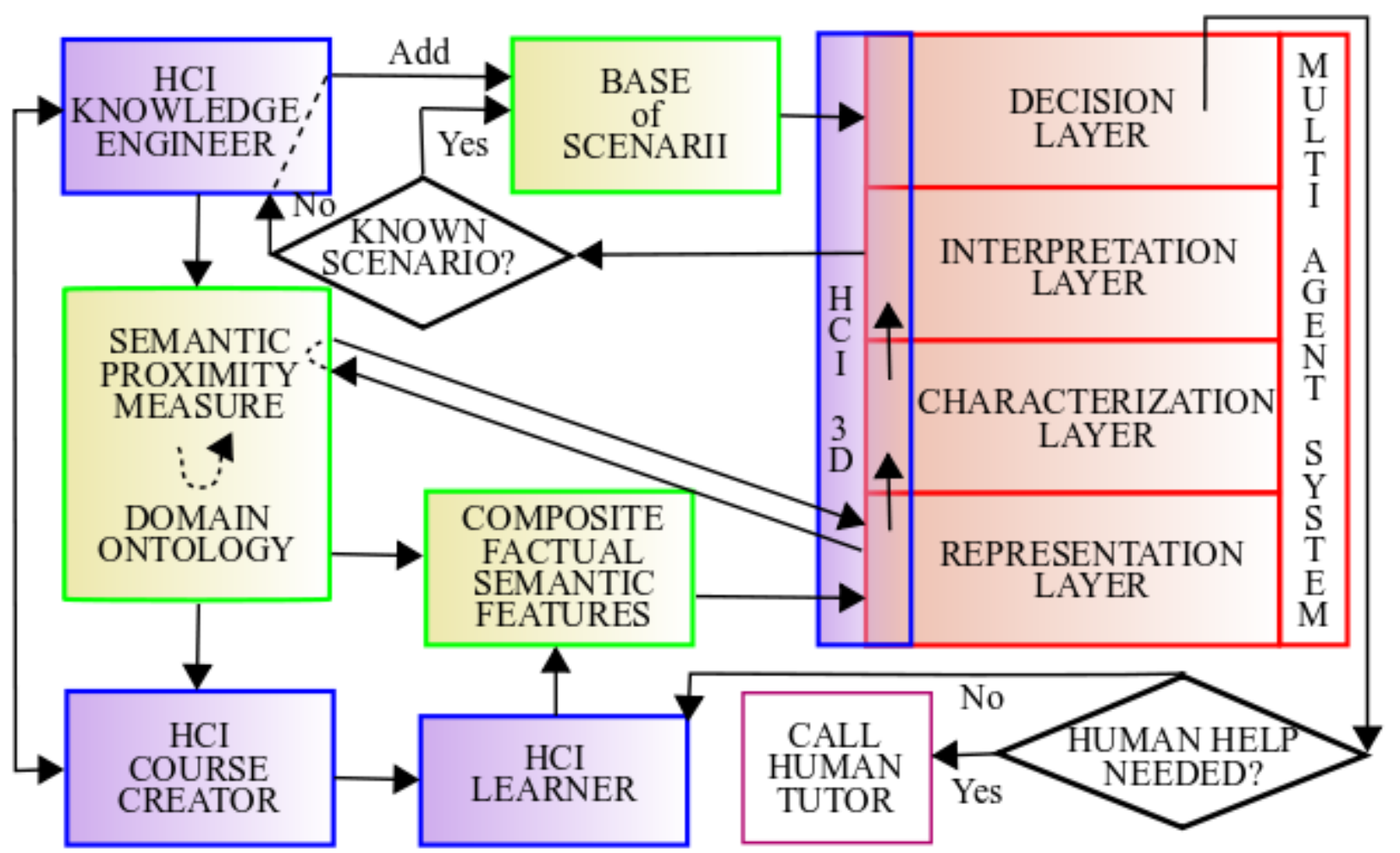

Figure 4. Architecture of the Intelligent Tutoring System 
The representation layer receives data from the learner as CFSFs. Each agent of the representation layer (factual agent: FA) keeps this atomic datum. Then the given FA computes internal indicators. Those indicators reflect the importance of the FSF in the whole representation. At any time, all FAs represent a snapshot of the situation. From a dynamic point of view, variations of internal indicators represent the evolution of the situation. In line with Wooldrigde, the ability to take in account this dynamic point of view is the reason why we choose MAS paradigm [18].

The structures of CFSFs are extracted from the domain ontology [19]. The knowledge engineer defines a semantic proximity measure used to compare CFSFs included into FAs. Related FAs according to this measure belong to the same semantic group.

The characterization layer classifies subsets of agents of the description layer according to levels of internal activity, and then, computes a synthetic measure characteristic of each subset. These clusters define a specific characterization of the current situation.

Using this characterization, the interpretation layer looks for similar scenarios in the database (Fig.5). If not recorded, the knowledge engineer can add this situation. Depending on the scenario, decision layer chooses either to call a human tutor or a non-human tutor or to adapt the learner's course. The decision layer can modify the learning tools at disposal for a student: suggesting new series of exercises, proposing complementary reading, taking evaluations again...

\section{CONCLUSION}

In 2010, the way our students use IT is not the same compared with the 90's. Addicted to their mobiles they send SMSs all day long. Competing for growing their Facebook relationship and experts in playing video games, they do prefer to stay at home facing their laptop instead of experiencing the real world with its real residents.

Building new systems for distance learning, we have to take into account these behavioral evolutions. Thus, we have designed GE3D. In addition to the above reasons we can notice that real actuators are too expensive. Furthermore, we cannot imagine beginners in PLC's training with a real complex industrial process. These good reasons justify our stand to use virtual equipments in GE3D world.

Unlike video games, where the efficiency of 3D renderings and physics engines counterbalance the weakness of the scenarios, the content must remain more important than the packaging. The pedagogical scenario described in this paper and implemented in GE3D can be easily modified. Its architecture can combine lectures, learning through projects (i.e. collaborative learning), learning with and from the peers (i.e. cooperative learning) and learning by problem solving.

Students prefer to learn by doing, on their own initiative and without being under the teacher's pressure. Nevertheless, they demand immediate help and attention from a tutor. The ITS implemented in GE3D is the facilitator for students and tutors to accomplish this.

Our next goal is to expand GE3D into a clustered web server to increase the number of connected people and to raise the system's reactivity.

\section{REFERENCES}

[1] “50 746 currently active sites among 215 countries including 9 120 in U.S., 3224 in U.K and 750 in France,” Retrieved July 11 ${ }^{\text {th }}$, 2010 from http://moodle.org/sites

[2] M. Llamas et al.,"Use of E-learning functionalities: results of a survey along spain,” Education Conference on Engineering EDUCON IEEE 2010, Madrid, 14-16 April 2010, E-ISBN: 978-14244-6570-5, Retrived July $11^{\text {th }}$, 2010 from doi:10.1109/ EDUCON.2010.5492359

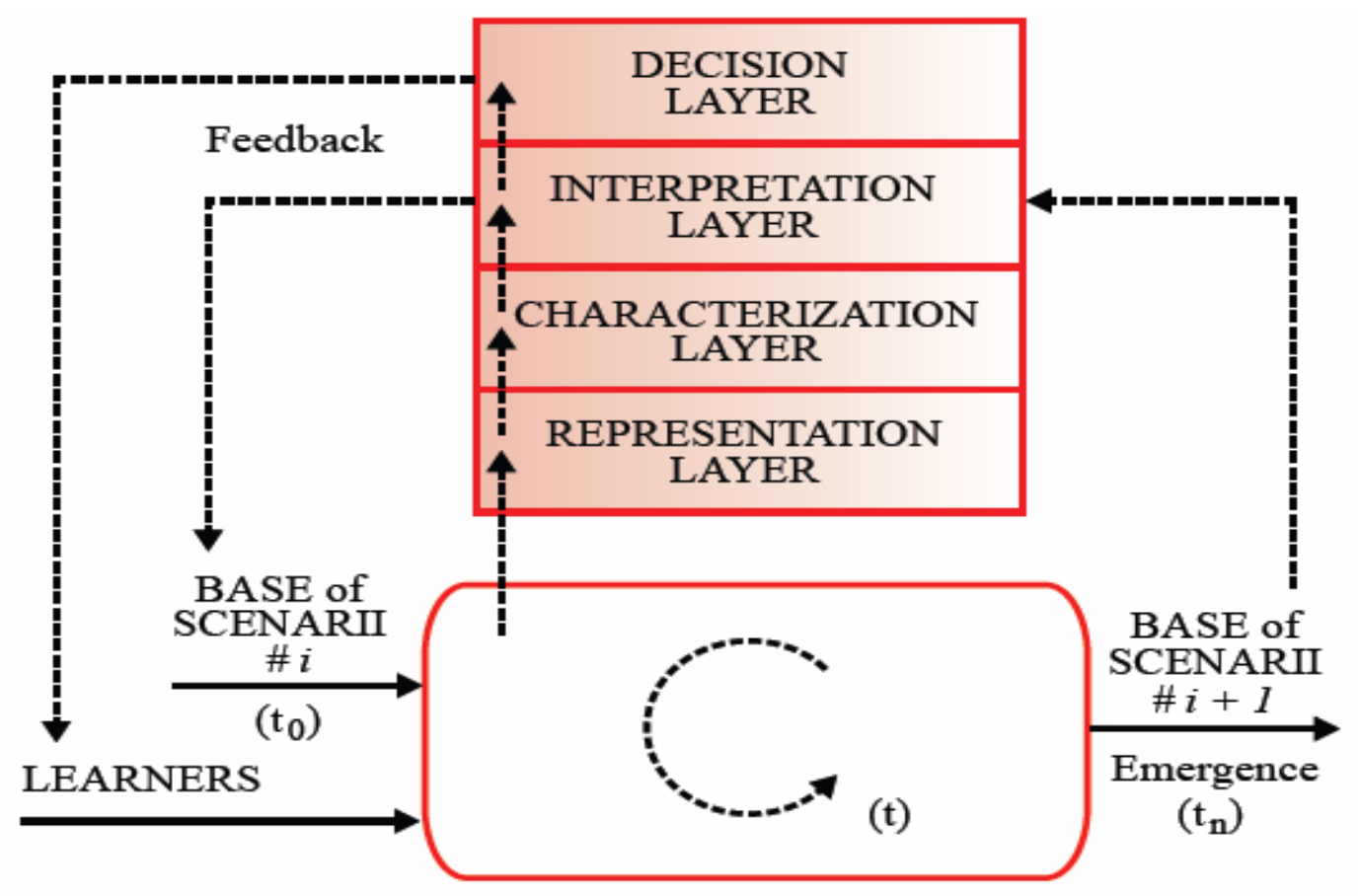

Figure 5. ITS feedback 
[3] T. Scheucher, P. H. Bailey, C. Gûtl, and V. J. Harward, "Collaborative virtual 3D environment for internet-accessible physics experiments,” International Journal of Online Engineering, vol. 5(1), 2009, pp. 65-71, Retrieved July $11^{\text {th }}, 2010$ from doi:10.3991/ijoe.v5s1.1014

[4] M. J. W. Lee, "How can 3D virtual worlds be used to support collaborative learning?,” Journal of e-Learning and Knowledge Society, vol. 5(1), 2009, pp. 149-158, Retrieved July $11^{\text {th }}, 2010$ from http://www.je-lks.it/en/09_01/3met_lee_ing09.pdf

[5] S. Bronack, R. Sanders, A.Cheney, R.Riedl, J. Tashner, and N. Matzen, "Presence pedagogy: teaching and learning in a 3D immersive world”, International Journal of Teaching and Learning in Higher Education, vol. 20(1), 2008, pp. 59-69, Retrieved July $11^{\text {th }}$, 2010 from http://www.isetl.org/ijtlhe/pdf/IJTLHE453.pdf

[6] B. Dalgarno, "The potential of 3D virtual learning environments: a constructivist analysis,” Electronic Journal of Instructional Science and Technology, vol. 5(2), 2002, pp. 3-6, Retrived July $11^{\text {th }}$, 2010 from http://www.usq.edu.au/electpub/e-jist/docs/Vol5_No2/ Dalgarno\%20-\%20Final.pdf

[7] E. Blümel, W. Termath, and T. Haase, "Virtual reality platforms for education and training in industry,” International Journal of advanced Corporate Learning, vol. 2(2), 2009, pp. 4-12, Retrieved July $11^{\text {th }}, 2010$ from doi:10.3991/ijac.v2i2.870

[8] SCOL technology, http://www.scolring.org

[9] S. Carr, "As distance education come of age, the challenge is keeping the students," The Chronicle of Higher Education, vol. 46(23), 2000, pp. A39-A41.

[10] J. Grieu, and F. Lecroq, "Campus numérique - campus virtuel : quel public ?,” CETSIS’ 05, Nancy, 25-27 octobre 2005, édition Edp Sciences, J3EA Journal sur l'enseignement des sciences et des technologies de l'information et des systèmes, vol. 5(2), ISSN (Electronic edition) : 1638-5705, Retrieved July $11^{\text {th }}, 2010$ from doi:10.1051/j3ea:2006050 or http://www.edpsciences.org/articles/ j3ea/abs/2006/03/contents/contents.html

[11] B. Riera, B. Vigario, J. P. Chemla, L. Correia, and F. Gellot, “10 ans de Maquettes Virtuelles pour l'enseignement des automatismes : deWINSIM en 1998 à ITS PLC Professional Edition en
2008,“ J3EA Journal sur l'enseignement des sciences et des technologies de l'information et des systèmes, 2008, Retrieved July $11^{\text {th }}, 2010$ from http://www.j3ea.org or doi:10.1051/j3ea:2008045

[12] A. Magalhães, B. Vigário, and F. Freitas, "3D virtual environments for PLC programming education and training," Proc. of European Simulation and Modelling Conf., 2005, pp. 349-353.

[13] K. Hafner, "Software tutors offer help and customized hints," The New York Times, September $16^{\text {th }}, 2004$, Retrived July $11^{\text {th }} 2010$ from http://www.nytimes.com/2004/09/16/technology/circuits/ 16tuto.html

[14] F. L. Bellifemine et al., "Developing Multi-Agent Systems With Jade,” New York: Wiley, 2007. doi:10.1002/9780470058411

[15] E. Wenger, “Artificial intelligence and tutoring systems,” Morgan Kaufmann, 1987.

[16] H. Boukachour, "Système de veille préventive pour la gestion de situations d'urgence : modélisation par agent,“ Ph.D. dissertation, LIH, Le Havre Univ., Le Havre, France, 2002.

[17] A. Aamodt, "Case-based reasoning and intellignet tutoring, “ AISSSLS Proceedings, Västeras, Sweden, 2005.

[18] M. Wooldridge, "An introduction to multiagent systems,“ 2nd ed. New York: Wiley, 2009.

[19] P. Person, H. Boukachour, M. Coletta, T. Galinho, and F. Serin, "Data Representation Layer in a MultiAgent Decision Support System, “ Multiagent and Grid Syst., vol. 2(3), 2006, pp. 223-235.

\section{AUTHORS}

Jean GRIEU, Florence LECROQ, Patrick PERSON, Thierry GALINHO and Hadhoum BOUKACHOUR are with the LITIS (Laboratoire d'Informatique, de Traitement de l'Information et des Systèmes), University of Le Havre, Le Havre, France :

Manuscript received July 14th, 2010. Published as resubmitted by the authors August 4th, 2010 